Article

\title{
A New Tool to Assess Maximum Permissible Solar PV Penetration in a Power System
}

\author{
Dhanuja Lekshmi J ${ }^{1, *(D)}$, Zakir Hussain Rather ${ }^{1, *}$ and Bikash C Pal ${ }^{2}$ \\ 1 Department of Energy Science and Engineering, Indian Institute of Technology Bombay, \\ Mumbai 400076, Maharashtra, India \\ 2 Department of Electrical and Electronic Engineering, Imperial College London, South Kensington, \\ London SW7 2BX, UK; b.pal@imperial.ac.uk \\ * Correspondence: dhanuja.lekshmi@iitb.ac.in (D.L.J.); zakir.rather@iitb.ac.in (Z.H.R.)
}

Citation: Lekshmi J, D.; Rather, Z.H.; Pal, B.C. A New Tool to Assess Maximum Permissible Solar PV Penetration in a Power System. Energies 2021, 14, 8529. https:// doi.org/10.3390/en14248529

Academic Editor: Tapas Mallick

Received: 19 October 2021

Accepted: 26 November 2021

Published: 17 December 2021

Publisher's Note: MDPI stays neutral with regard to jurisdictional claims in published maps and institutional affiliations.

Copyright: (c) 2021 by the authors. Licensee MDPI, Basel, Switzerland. This article is an open access article distributed under the terms and conditions of the Creative Commons Attribution (CC BY) license (https:// creativecommons.org/licenses/by/ $4.0 /)$.

\begin{abstract}
With diminishing fossil fuel resources and increasing environmental concerns, largescale deployment of Renewable Energy Sources (RES) has accelerated the transition towards clean energy systems, leading to significant RES generation share in power systems worldwide. Among different RES, solar PV is receiving major focus as it is most abundant in nature compared to others, complimented by falling prices of PV technology. However, variable, intermittent and nonsynchronous nature of PV power generation technology introduces several technical challenges, ranging from short-term issues, such as low inertia, frequency stability, voltage stability and small signal stability, to long-term issues, such as unit commitment and scheduling issues. Therefore, such technical issues often limit the amount of non-synchronous instantaneous power that can be securely accommodated by a grid. In this backdrop, this research work proposes a tool to estimate maximum PV penetration level that a given power system can securely accommodate for a given unit commitment interval. The proposed tool will consider voltage and frequency while estimating maximum PV power penetration of a system. The tool will be useful to a system operator in assessing grid stability and security under a given generation mix, network topology and PV penetration level. Besides estimating maximum PV penetration, the proposed tool provides useful inputs to the system operator which will allow the operator to take necessary actions to handle high PV penetration in a secure and stable manner.
\end{abstract}

Keywords: frequency stability; maximum penetration level; renewable energy sources; solar PV; voltage stability

\section{Introduction}

The requirement of an environmentally friendly and sustainable energy generation to meet the ever-growing global energy needs has directed focus on renewable energy sources (RES), particularly solar PV and wind which are commercially well established and are proven technologies for clean power generation. The global statistics of RES addition in 2020 alone shows unprecedented momentum in transition of power sector with a total capacity addition of $260 \mathrm{GW}$ of RES (127 GW solar and $111 \mathrm{GW}$ of wind) despite the COVID-19 pandemic impact [1,2]. Solar PV generation is gaining immense popularity among all other RE power sources mainly due to its abundant availability, green nature and smooth noiseless operation, along with advancements in PV panel manufacturing and their falling cost. Moreover, various advantages of solar PV technology such as ease of installation, absence of moving mechanical parts, comparably less maintenance and operation requirements, etc., have paved the way for its tremendous growth [3].

The operation of power system worldwide is moving closer ever to their security level, primarily due to RES-driven displacement of conventional power plants. Several techniques such as maximum power point tracking algorithms, advanced tracking techniques using artificial neural networks, controllers based on adaptive neuro fuzzy interface 
systems, etc., have been developed for increasing power generation from solar PV power plants [4]. However, increasing solar PV penetration into the existing power grid will result in several challenges to its stable and reliable operation such as oscillatory instability and small signal stability issues [5-9]. Higher PV penetration levels in distribution networks directly affect equipment like load tap changers, line voltage regulators and voltage controlled capacitor banks as they operate to maintain system voltages within the limits [7].

Solar PV penetration level in an existing power grid cannot be increased arbitrarily due to a number of technical issues. One such major issue in a highly solar PV penetrated power system is the diminished inertia of the system due to limited number of committed synchronous generators. Another issue is lack of sufficient generation reserve margin that can impact frequency stability of the power system [9]. The South Australian blackout occurred in Sept 2016, which recorded a high Rate of Change of Frequency (RoCoF) of 6 $\mathrm{Hz} / \mathrm{s}$, proving that synchronous inertia adequacy is a serious concern for power systems with higher RE penetration having limited synchronous generators. The instantaneous penetration level of solar PV and wind combined was more than $50 \%$ before the blackout which occurred because of the lighter South Australian power system, with only three online thermal power plants [10].

Thus, it is essential to identify the maximum possible instantaneous RE penetration level under the existing grid infrastructure which can ensure safe, secure and reliable operation even during severe contingencies. The regulatory authorities should tackle such issues through adequate grid code regulations [11] and market arrangements, incorporating alternate sources of ancillary / flexibility services coupled with grid infrastructure upgradation wherever inevitable [12,13]. The authors of [14] discuss a model for wind and solar photovoltaic energy integration in Romania from the promoting scheme point of view, which gives an indication for WPP and PV installed power in the near future. Such mechanism of RES promoting scheme consists of mandatory quotas which energy suppliers should acquire, estimation of electricity consumption and annual operating time at maximum capacity of each RES type.

A number of studies have been carried out to identify maximum allowable wind penetration level in an existing power grid [15-21]. H. Ahmedi et al. [15] determined the maximum admissible wind energy penetration level based on evaluation of frequency security constraints and transient stability limits, whereas voltage stability-based analysis using system capacity calculations are utilized for evaluating maximum wind penetration level in [16,17]. A Particle Swarm Optimization-based control algorithm is proposed in [18] for maximizing wind energy penetration level and [19] presents a method for effective wind farm sizing in a weak power grid using modal analysis. To assess maximum wind penetration level using available information of the corresponding power generation system, an integrated numerical algorithm is developed and presented in [20]. With the help of a computational algorithm based on frequency response of power system, proposed approach in [21] evaluates maximum wind energy penetration level. A new tool is proposed in [22] to estimate highest margin of instantaneous wind power level in the system with respect to frequency response adequacy of the grid. This tool uses inertia and headroom information as input to provide the maximum wind power level. Using this tool, a Transmission System Operator (TSO) could evaluate a secure wind penetration threshold that can be integrated at a particular load level as soon as system generation profile is known.

It is evident from the literatures that the increase in wind penetration level in a conventional grid influences frequency stability, voltage stability and transient stability of the grid, hence these stability parameters have been used individually as suitable attributes for assessing maximum margin of wind power level that can be integrated into the system. However, none of the studies has considered all these criteria together or combination of them in estimation of maximum allowable wind penetration in a power system. It is also equally important to assess the maximum permissible solar PV penetration level that can be integrated into an existing grid. In this backdrop, this work aims to present a 
tool/framework to estimate maximum permissible solar PV penetration level $\left(\mathrm{PV}_{\mathrm{max}}\right)$ in a power system without changing its existing infrastructure. In this study, the various aspects of transient stability, voltage stability and frequency stability were considered and assessed for a power system under different large-scale solar PV penetration levels. The proposed methodology considers both frequency stability as well as voltage stability aspects for evaluating $\mathrm{PV}_{\max } \%$ which can be a useful tool for the transmission system operators.

The rest of the paper is organized as follows. In Section 2, the overview of the study system modeling is described. Section 3 illustrates the methodology and stability analysis followed by details of the proposed tool in Section 4 . The simulation results are discussed and validated in Section 5 and the study is concluded in Section 6.

\section{System Modeling}

In this work, the studied power system is developed considering detailed dynamic models of conventional synchronous generators and large-scale solar PV power plants. The generic PV system models provided by Western Electricity Coordinating Council (WECC) Renewable Energy Modeling Task Force (REMTF) and the International Electrotechnical Commission (IEC) Technical Committee (TC) 88, Working Group (WG) 27 are adopted, which present a guideline for representation of transmission-connected largescale PV plants for bulk system load flow simulations [23,24]. In order to develop timedomain simulation model for bulk power system studies, the central station PV plants are recommended to be represented by a single equivalent PV generator connected at Point of Interconnection. The overall model structure of the implemented large-scale PV plant is shown in Figure 1.

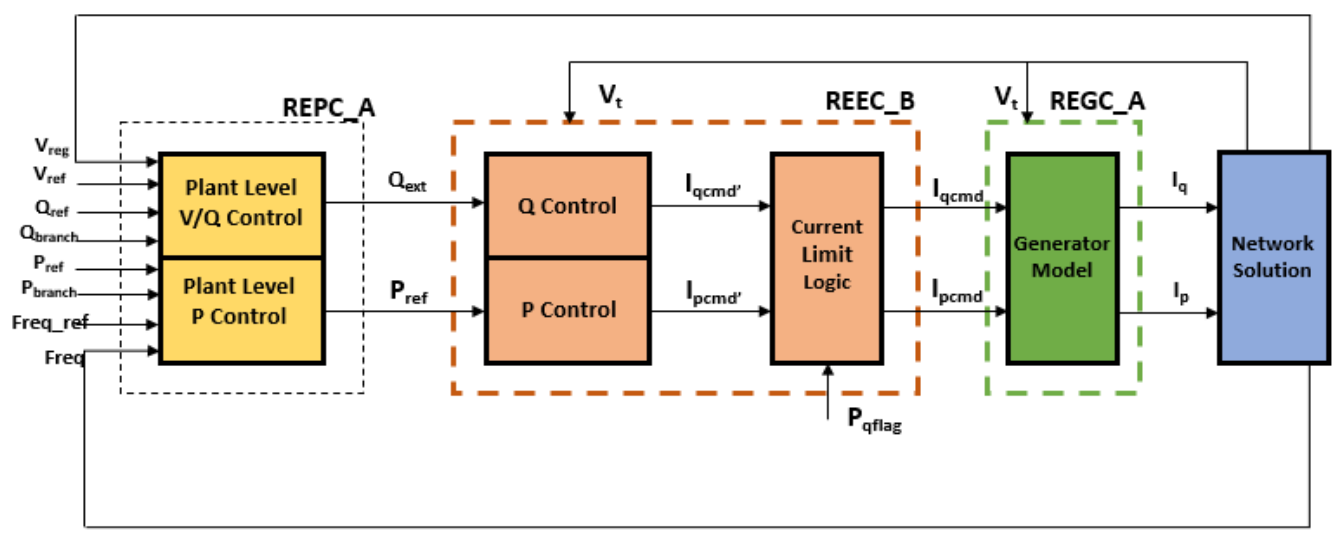

Figure 1. Block diagram for central station PV system model. Adapted from Ref. [24].

The Renewable Energy Generator/Converter module (REGC_A) is simply a high bandwidth current regulator. This part of the model injects the real and reactive components of the inverter currents into external network during the network solution in response to real and reactive current commands from electrical control model. The Renewable Energy Electrical Control module (REEC_B) consists of a local active power control and a local reactive power control. It generates the active and reactive current command signals which will then be given to generator converter model which injects real and reactive currents into the external network. As per the LVRT regulation requirements, the value of a user-specified flag denoted by PQ flag can be set, thus choosing between active power priority and reactive power priority. Renewable Energy Plant Control module (REPC_A) is an optional model depending on whether a plant level control is implemented or not. In the study presented here, this block is not implemented.

The WECC generic solar PV plant model is implemented in the DIgSILENT PowerFactory software and the studies have been carried out on a modified IEEE 39 bus system (IEEE TF, 2013). The 39 bus New England System is a simplified model of the high voltage transmission system in the north-east of the USA (New England area) which consists of 
10 generators, 19 loads, 34 lines and 12 transformers. The generator, G 01, connected at bus number 39 represents the rest of the interconnected system in USA and Canada. All the generators in this standard system are modeled as 6th order synchronous machines equipped with standard IEEE models of automatic voltage regulators, excitation systems, governor systems and power system stabilizers.

In this research work, to realize different solar PV penetration levels, the New England System is modified by replacing some of the synchronous generators with grid code compliant WECC large-scale PV system models. The generators numbered 3, 4, 6, 8 and 9 had been displaced by adding ten PV models at bus numbers 33, 23, 2, 20, 35, 19, 21, 37,38 and 8 , respectively, by increasing penetration level up to $60 \%$ in steps of $10 \%$. The placement of solar PV systems was based on voltage sensitivity analysis and existing transmission line constraints. These buses are identified by applying three-phase faults at each of the buses and observing corresponding voltage heat map. From the heat map, the buses which resulted in higher voltage dips at the remaining nodes of the system due to the applied fault are considered as weak buses and are used for placing PV systems. The single line diagram of modified solar PV integrated $50 \mathrm{~Hz}$ study system is shown in Figure 2 .

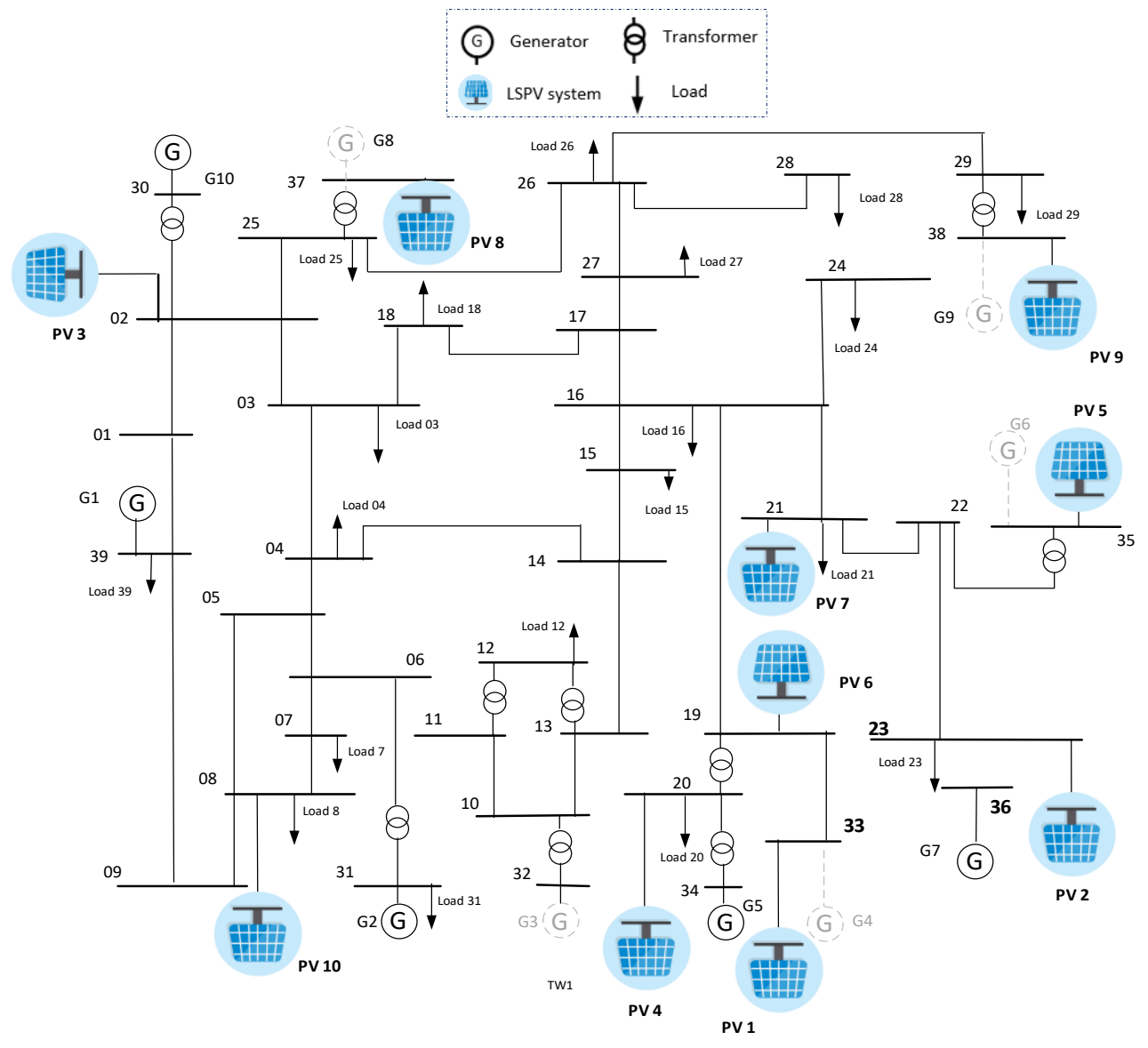

Figure 2. Modified solar PV integrated New England system.

\section{Methodology and Stability Analysis}

This section presents in detail the methodology adopted for developing the tool to estimate $\mathrm{PV}_{\max \%}$ for a given power system. In this study, large-scale solar PV penetration level has been calculated based on total PV power integrated to the system by replacing the synchronous machines with respect to the total system demand. In order to determine maximum possible penetration level of solar PV that can be accommodated in the existing infrastructure, the impact of increased penetration on various factors such as rotor angle, 
voltage and frequency of the network are investigated. Various case studies are carried out to analyze stability and security of the power system following different contingencies under significant PV levels thereby to identify most relevant attributes or criteria which can be used to assess limiting PV levels to be integrated to the power system under all operating conditions. The following stability analysis has been considered in estimation of $\mathrm{PV}_{\max \%}$ :
(a) Transient rotor angle stability;
(b) Dynamic voltage security/severity;
(c) Frequency stability.

These analyses are carried out for all possible operating conditions considering various combinations of generation mix of solar PV penetration and Conventional Power Plant (CPP) generation. The security of the system is evaluated for each operating condition and are then classified into secure/insecure cases. Table 1 provides a summary of the different combinations of study cases used for conducting stability/security analysis. The step by step procedure of the evaluation of secure/insecure cases is as follows:

i. Define different operating conditions of test system by varying the generation mix of solar PV (0-60\%) and CPP (40-100\%).

ii. Under each operating condition, apply 3-phase short circuit fault according to conditions mentioned in Table 1.

iii. Calculate various stability/security indices as explained in Sections 3.1-3.3. Based on the thresholds defined for these indices, classify the operating conditions as secure or insecure case.

iv. Calculate percentage of secure/stable cases for each operating condition using Equation (1)

$$
\text { Secure Cases } \%=\frac{\text { Total number of secure cases }}{\text { Total number of study cases }} \times 100
$$

Table 1. Summary of the various fault conditions used for the stability/security analysis.

\begin{tabular}{cc}
\hline Fault Settings & Conditions \\
\hline Fault Type & 3-phase short circuit \\
Fault Location & All $39 \mathrm{buses}$ \\
Retained Fault Voltages & $0 \mathrm{pu}, 0.3 \mathrm{pu}, 0.5 \mathrm{pu}, 0.7 \mathrm{pu}$ \\
Fault Durations & $150 \mathrm{~ms}, 600 \mathrm{~ms}, 900 \mathrm{~ms}, 1200 \mathrm{~ms}$ \\
\hline
\end{tabular}

\subsection{Transient Rotor Angle Stability}

The first case study is carried out to investigate the impact of higher penetration of solar PV in the system on transient rotor angle stability. There are a number of studies addressing the issue of rotor angle stability with increased PV generation [25-27], however, the reported studies have analyzed each stability issue instead of taking a holistic approach for all the stabilities. The transient instability occurs when generator rotor angle exceeds the critical value, and this is usually investigated in time duration of 3-5 s following any fault or disturbance.

In order to evaluate the transient stability of a network, rotor angle of synchronous generator measured with respect to synchronously rotating reference frame is considered. During severe transient events, such as severe 3-phase faults, generator rotor angle oscillates between $180^{\circ}$ to $-180^{\circ}$ with respect to rotor angle of reference machine in the system. Since the evaluation of all individual rotor angles is a cumbersome process, a method based on maximum rotor angle difference proposed in [28] is used to carry out the study. In 
this method, an index is defined in terms of maximum rotor angle separation in degrees between any two machines in the system and is given by the following formula:

$$
\mathrm{TSI}=\frac{\left(360-\Delta \delta_{\max }\right)}{\left(360+\Delta \delta_{\max }\right)} \times 100 \%
$$

where TSI represents Transient Stability Index whose value varies between (0-100) percent and $\Delta \delta_{\max }$ is maximum angle separation of any two rotor angles.

As mentioned in Section 3, a vast range of operating conditions are created by varying PV penetration levels from 0 to $40 \%$ and by applying 3-phase faults at all the 39 buses of the test system by varying voltage dips and fault durations. For a given contingency, if the value of calculated TSI is less than $10 \%$, network is considered transiently unstable. A total of 312 fault cases are simulated for a single generation mix of the test system and number of stable and unstable cases identified using TSI is expressed as a percentage of total fault cases. The summary of obtained results is shown in Figure 3. It can be clearly observed from the chart that number of stable cases is reduced with rise in PV penetration level, i.e., when solar PV penetration in the system increases, transient stability is worsened.

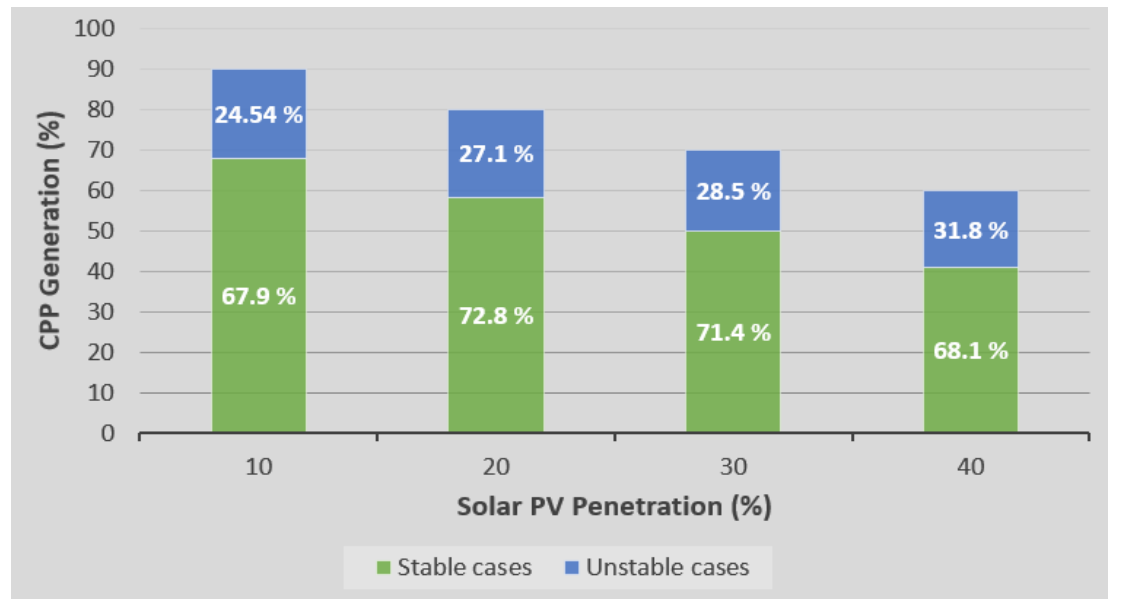

Figure 3. Summary of transient stability analysis for different PV penetration levels.

It is a well-known fact that transient stability is highly dependent on fault proximity and severity [28]. To observe this dependency, some random sample cases are considered by applying 3-phase fault for a duration of $300 \mathrm{~ms}$ and a retained voltage of $0.3 \mathrm{pu}$ at various buses in the test system. The TSI values are calculated using Equation (2) for all simulated fault cases and the obtained values are given in Table 2. According to TSI values listed in the table, a clear reduction of transient stability is observed with the increase of solar PV penetration for a fault at any of the critical locations of the network. On the contrary, for a fault at less critical location, transient stability has improved. So, it can be concluded that integration of PV plants shows both adverse and beneficial effects on transient stability performance of system depending on fault proximity, severity and duration of fault.

Table 2. TSI values for different solar PV penetration levels.

\begin{tabular}{|c|c|c|c|c|c|}
\hline \multirow{7}{*}{ TSI } & \multicolumn{5}{|c|}{ Retained Fault Voltage $=0.3$ pu; Fault Duration $300 \mathrm{~ms}$} \\
\hline & Fault Location & 0\% PV & $10 \% \mathrm{PV}$ & $20 \% \mathrm{PV}$ & $30 \% \mathrm{PV}$ \\
\hline & Bus 01 & 62.7 & 61.5 & 64.7 & 59.1 \\
\hline & Bus 12 & 65.46 & 62.64 & 62.35 & 61.38 \\
\hline & Bus 20 & 40.87 & 47.66 & 50.38 & 56.56 \\
\hline & Bus 33 & 50.22 & 63.8 & 65.69 & 67.84 \\
\hline & Bus 39 & 63.54 & 62.9 & 63.02 & 58.4 \\
\hline
\end{tabular}




\subsection{Dynamic Voltage Severity/Security}

The operation of power systems worldwide is subjected to increased stress levels due to several reasons, such as increase in demand, integration of renewables, reduction of conventional power plants, etc. Along with these operating and infrastructure changes, severe contingencies and their effects lead power grid to further stressed levels, sometimes to the extent of collapse. The system may undergo severe voltage sags, under and over voltages, voltage instability or sometimes complete voltage collapse during various contingencies or transient events such as system faults. Owing to the increased penetration of renewables into existing grid infrastructure, more and more voltage instability related issues are experienced by power systems all over the world.

For static and dynamic voltage stability assessment, a number of methods are reported in literature [29-31]. Abnormal state of a power system is reflected by its voltage deviation during a contingency, and for severe dynamic conditions, criteria defined by NERC for assessment of transient voltage dip following a contingency is considered. In this study, an index is used to quantify system voltage limit violations which is derived from observed transient response of all system bus voltages. The voltage severity index (VSI) is defined as follows:

$$
\mathrm{VSI}=\left\{\begin{array}{cc}
\left|\mathrm{V}_{0}-\mathrm{V}_{\mathrm{dev}}\right| / \mathrm{V}_{0} & \text { if }\left|\mathrm{V}_{0}-\mathrm{V}_{\mathrm{dev}}\right| / \mathrm{v}_{0} \geq 0.25 \\
0 & \text { otherwise }
\end{array}\right.
$$

As per NERC $(\mathrm{N}-1)$ contingency criteria, buses with a VSI greater than 0.25 during transient period following a fault are considered as severe buses. In this analysis, various fault conditions as given in Table 1 for various system operating conditions are simulated and based on the value of VSI calculated using Equation (3); secure buses are identified in order to assess dynamic security of the test system. For each PV penetration level varying from $0-60 \%$ and for each retained fault voltage conditions $(0-0.7 \mathrm{pu})$, the number of secure cases are expressed as a percentage of the total cases studied. Results obtained are indicated in Figure 4. The chart clearly shows how number of secure cases reduced with increase in $\mathrm{PV}$ penetration level for various retained fault voltages.

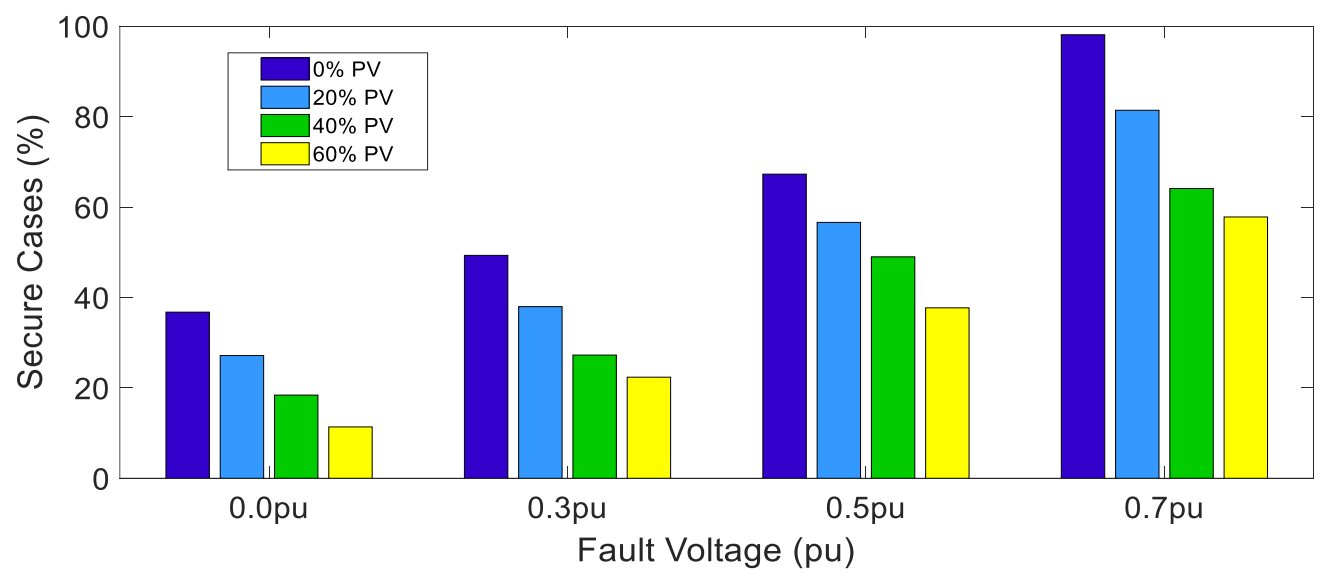

Figure 4. Percentage of secure cases for various PV penetration levels based on VSI.

The index VSI will give estimation of how severely the power system is affected with voltage dip resulted from various fault conditions, while another criterion is used in this study to identify whether system is secure or not under a given fault/contingency based on magnitude and duration of the voltage deviation. For any bus, if the voltage is outside the limits of $0.8 \mathrm{pu}$ and $1.1 \mathrm{pu}$ for more than $0.5 \mathrm{sec}$, the system is considered to be insecure under that contingency.

Figure 5 is a plot of voltage profile of a number of buses under a sample study case to illustrate how the dynamic voltage security has been evaluated for the analysis part. As indicated in figure, for a fault applied at bus 2, the duration of voltages at bus 35 and 
36 staying at a value more than $1.1 \mathrm{pu}$ is almost $1 \mathrm{sec}$ and hence, system is considered to be insecure for this particular fault scenario. Based on this criterion, the study cases are divided into secure and insecure cases considering duration of dynamic voltage deviations after fault clearance, and the summary of this analysis is represented in Figure 6. For various PV penetration levels, the number of secure cases are expressed as a percentage of total simulated cases, based on post fault voltage deviations and its duration as mentioned above. It is evident from the figure that the number of secure cases significantly decreased with increasing PV levels.

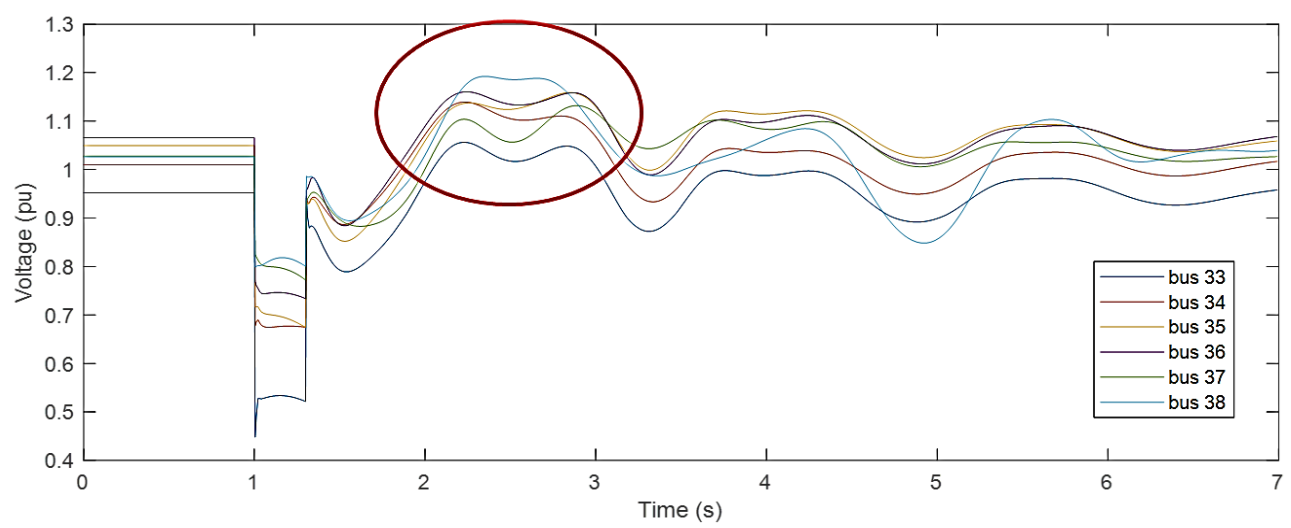

Figure 5. Voltage profiles of various buses during a 3-phase fault at bus 2.

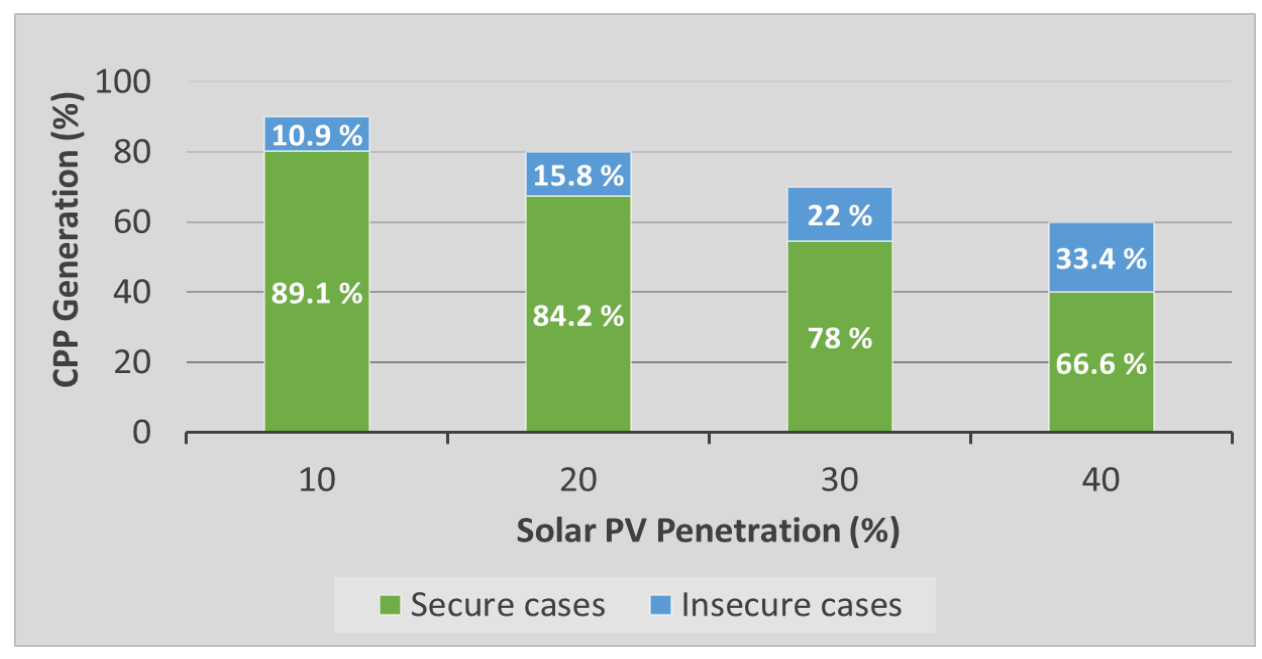

Figure 6. Summary of dynamic voltage security analysis for different PV penetration levels.

\subsection{Frequency Stability}

As installed capacity of variable generation increases with solar PV-driven displacement of synchronous machines in power grid, total rotational inertia and primary frequency reserves (PFR) which are essential to stabilize grid frequency reduces. This reduction in system inertia and PFR could lead to significant instability issues in large grids with high levels of PV generation or low-inertia grids such as islands like Hawaii [32], Puerto Rico [33], etc. In this study case, potential risk of frequency instability is analyzed in a large-scale solar $\mathrm{PV}$ integrated network by carrying out a number of different fault scenarios as outlined in Table 1. The parameters used for analyzing the frequency stability of the system are Rate of Change of Frequency (RoCoF), frequency nadir/zenith and time taken to reach nadir/zenith points following a fault occurred in the system. Cases where maximum RoCoF exceeds $+/-0.5 \mathrm{~Hz} / \mathrm{s}$ or frequency nadir/zenith points exceeds thresholds set by grid codes are considered as insecure cases. These secure/insecure cases are then expressed 
as a percentage of total simulated cases which is represented in Figure 7. This figure shows that frequency stability is also affected by increase in PV penetration level as number of secure cases decreases with increasing PV levels in the system mainly due to reduction in inertial support.

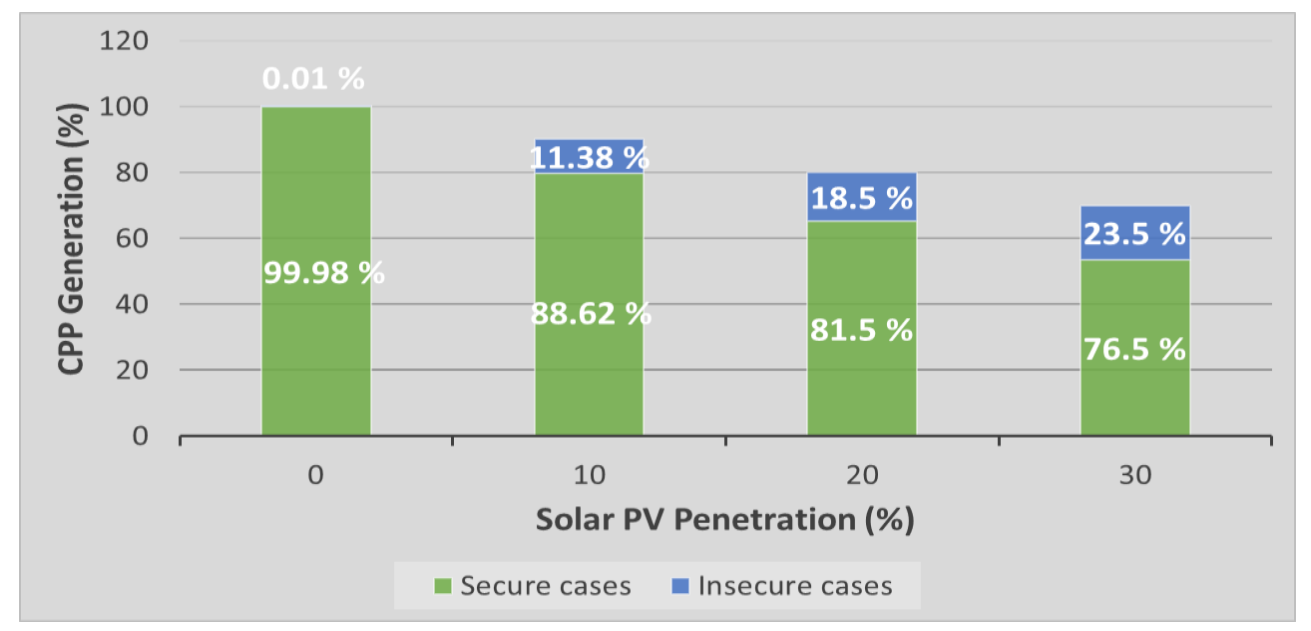

Figure 7. Summary of frequency stability analysis for different PV penetration levels.

\section{Proposed Tool to Estimate $\mathbf{P V}_{\max \%}$}

The stages associated with proposed $\mathrm{PV}_{\max \%}$ estimation framework are sequentially presented in this section. From the observations of stability case studies explained in Sections 3.1-3.3, it is evident that among transient rotor angle stability, dynamic voltage security and frequency stability, the former parameter cannot be used as a deciding factor to accurately estimate $\mathrm{PV}_{\max }$ as it has both positive and negative impacts with higher dependency on other factors such as location, duration, etc., of the contingencies. Thus, the proposed estimation method is comprised of two stages where both voltage security and frequency stability are considered as driving factors to assess $\mathrm{PV}_{\max \%}$. In stage 1 of the tool, the highest PV penetration level is determined by ensuring sufficient frequency response which will keep the frequency nadir at its defined limits for any load conditions in the grid whereas stage 2 evaluates a secure and safe PV penetration limit that the grid can handle at any load conditions by maintaining its dynamic voltage security.

\subsection{Stage 1: Frequency Nadir-Based $P V_{\text {max } \%}$ Estimation}

In a power system, an imbalance between total power generation and total load demand due to system disturbances such as load changes, faults, or generator trips, may aggravate frequency excursions and lead to significant load shedding issues. In order to maintain a satisfactory frequency quality and to make sure system operates in a safe manner, frequency deviations should be retained within specified limits. In modern power systems with increased installation of inverter interfaced devices, the inertia is significantly reduced, increasing the probability of a higher frequency nadir following serious system disturbances. The ability of a power system to arrest such rapid frequency changes and stabilize the grid following serious system events are known as frequency response [34] and is dependent on two major factors: (i) the amount of stored kinetic energy (KE) that the committed synchronous generators can release into the system during a frequency event, also known as inertial response and (ii) the available power reserve (PR) from the committed online synchronous generators which is the difference between its rated power output and actual power output. The frequency nadir $\left(\mathrm{F}_{n}\right)$ of a power system relies on the total power imbalance resulted due to the disturbance as well as KE and PR of the network as all these measures jointly control the frequency response of the grid. Hence it is rational to conclude that the PV penetration level can also be correlated to frequency nadir of the grid, thereby connecting it to KE and PR of system thus making it a major element that 
can be used to estimate the maximum permissible PV penetration level, $\mathrm{PV}_{\max \%}$ for an existing grid.

The step by step procedure to assess $\mathrm{PV}_{\max \%}$ of a power grid using the frequency nadir is presented here. The detailed algorithm explaining stage 1 estimation is given in Figure 8 .

Step 1: A number of different load scenarios are created by varying the load and generation profiles for the test system developed in DIgSILENT PowerFactory (Version 2019, DIgSILENT GmbH, Gomaringen, Germany). The maximum and minimum demand of the studied system is around $6097 \mathrm{MW}$ and $4627 \mathrm{MW}$, respectively. The total load of the studied system is calculated as a net aggregation of its local loads and interconnection power flows. The power dispatch from conventional generators and integrated solar $\mathrm{PV} /$ wind sources are adjusted to generate different load cases for the analysis purpose. For each load case, the KE and PR values are computed using the following equations:

$$
\begin{gathered}
\mathrm{KE}=\sum_{\mathrm{i}=1}^{n}\left(\mathrm{~S}_{\mathrm{i}} \times \mathrm{H}_{\mathrm{i}}\right) \\
\mathrm{PR}=\sum_{\mathrm{i}=1}^{n_{g}}\left(\mathrm{P}_{\text {rated }, \mathrm{i}}-\mathrm{P}_{\text {gen, } \mathrm{i}}\right)
\end{gathered}
$$

where $S_{i}$ is the rated power in MVA and $H_{i}$ is inertia constant in seconds of $i^{\text {th }}$ synchronous generator, $n$ is the total number of online committed synchronous generators at a particular load scenario. Similarly, $\mathrm{P}_{\text {rated,i }}$ and $\mathrm{P}_{\text {gen,i }}$ are the rated power output and actual generated power output in $\mathrm{MW}$ of the respective $\mathrm{i}^{\text {th }}$ generator in the system. $n_{g}$ denotes number of synchronous generators with enabled governor control or primary frequncy control. The following assumptions are made while calculating KE and PR for each load case:

i. For a particular load case, the number of committed synchronous generators remains constant thereby keeping KE constant.

ii. Under a specific load case, the PV penetration level is increased by only changing the dispatch power of committed synchronous generator. Thus, the PR values change with change in PV penetration level.

iii. Rate of Change of Frequency (RoCoF) is considered to be more dependent on the KE of the system and not PR. Hence for a specific load scenario, RoCoF changes are not considered as significant as changes in Frequency Nadir.

Under every load case considered, a system disturbance is simulated by disconnecting the largest generator and corresponding frequency nadir is measured. A multi-variable regression model is developed by using these measured frequency nadir values $\left(F_{n}\right)$, calculated KE and PR values and corresponding power outage values $\left(\mathrm{P}_{\mathrm{o}}\right)$ as shown in Equation (6) where $f_{1}$ denotes a functional relation and is termed as model 1 in this paper. The Centre of Inertia Frequency (CoIF) defined in [35] is used for measuring system frequency nadir values in order to eliminate the effect of small signal oscillations.

$$
\mathrm{F}_{\mathrm{n}}=f_{1}\left(\mathrm{P}_{\mathrm{o}}, \mathrm{KE}, \mathrm{PR}\right)
$$

Step 2: As a next step, a mathematical relation is developed between solar PV penetration level and PR of the system under each load case. The solar PV penetration level is calculated as a ratio of total installed capacity of PV power in the system to the total load demand of the system given by Equation (7) as follows:

$$
\mathrm{PV}_{\%}=\frac{\text { Total installed capacity of PV power }(\mathrm{MW})}{\text { Total demand }(\mathrm{MW})} \times 100
$$

The maximum PV penetration level $\left(\mathrm{PV}_{\mathrm{max}} \%\right.$ is defined as the highest value of instantaneous PV power that can be integrated into a power system while maintaining system frequency or rate of change of frequency within its tolerable limits during and after a 
disturbance. In this study, frequency nadir limits are considered for estimating secure $\mathrm{PV}_{\max }$ for the test system. For determining $\mathrm{PV}_{\max }$ at a specific load scenario, two separate mathematical relations are formed between $P V_{\%}$ and $F_{n}$ and $P R$ and $F_{n}$ by simulating largest generator outage cases under different PV penetration levels. It is important to note that the PV penetration level is incremented only by changing power dispatch from committed synchronous generators under a specific load case thereby maintaining the value of KE constant and PR varying. The mathematical relations are formed and indicated by Equations (8) and (9) as follows:

$$
\begin{gathered}
\mathrm{F}_{\mathrm{n}}=f_{2}(\mathrm{PR}) \\
\mathrm{F}_{\mathrm{n}}=f_{3}\left(\mathrm{PV}_{\%}\right)
\end{gathered}
$$

where $f_{2}$ and $f_{3}$ represents a functional relation obtained using linear regression model.

Step 3: Using Equations (8) and (9), and by equating $F_{n}$ to a lower limit of permissible system frequency nadir value, the minimum $\mathrm{PR}$ required $\left(\mathrm{PR}_{\min }\right)$ and maximum $\mathrm{PV}$ penetration level $\left(\mathrm{PV}_{\max }\right)$ that can be added to the system which will ensure secure frequency response under the specified load scenario is calculated. Now, as a final step, another mathematical relation denoted by $f_{4}$ (Model 2) is developed between obtained $\mathrm{PR}_{\min }$ and $\mathrm{PV}_{\max \%}$ corresponding to each of the load cases simulated as indicated in Equation (10) below:

$$
\mathrm{PV}_{\max \%}=f_{4}\left(\mathrm{PR}_{\min }\right)
$$

Step 4: The last step involves prediction of maximum PV penetration level at any load level of the system under consideration. Through market bidding, the system operator will be able to obtain available KE value from unit commitment and economic dispatch schedule at any load levels. Moreover, by considering a worst case scenario of largest generator outage of the system, the power imbalance $P_{o}$ is determined. At first, model 1 (Equation (6)) is used and the value of PR is calculated considering under frequency load shedding (UFLS) limit for $F_{n}$. Then this value of PR is used as input in model 2 to generate $\mathrm{PV}_{\max \%}$ as output. Figure 9 indicates an input-output diagram of this approach.

This entire procedure will give the value of maximum permissible PV penetration level that can be integrated instantaneously to the power system by ensuring secure frequency response of the system under the specified load scenario. 


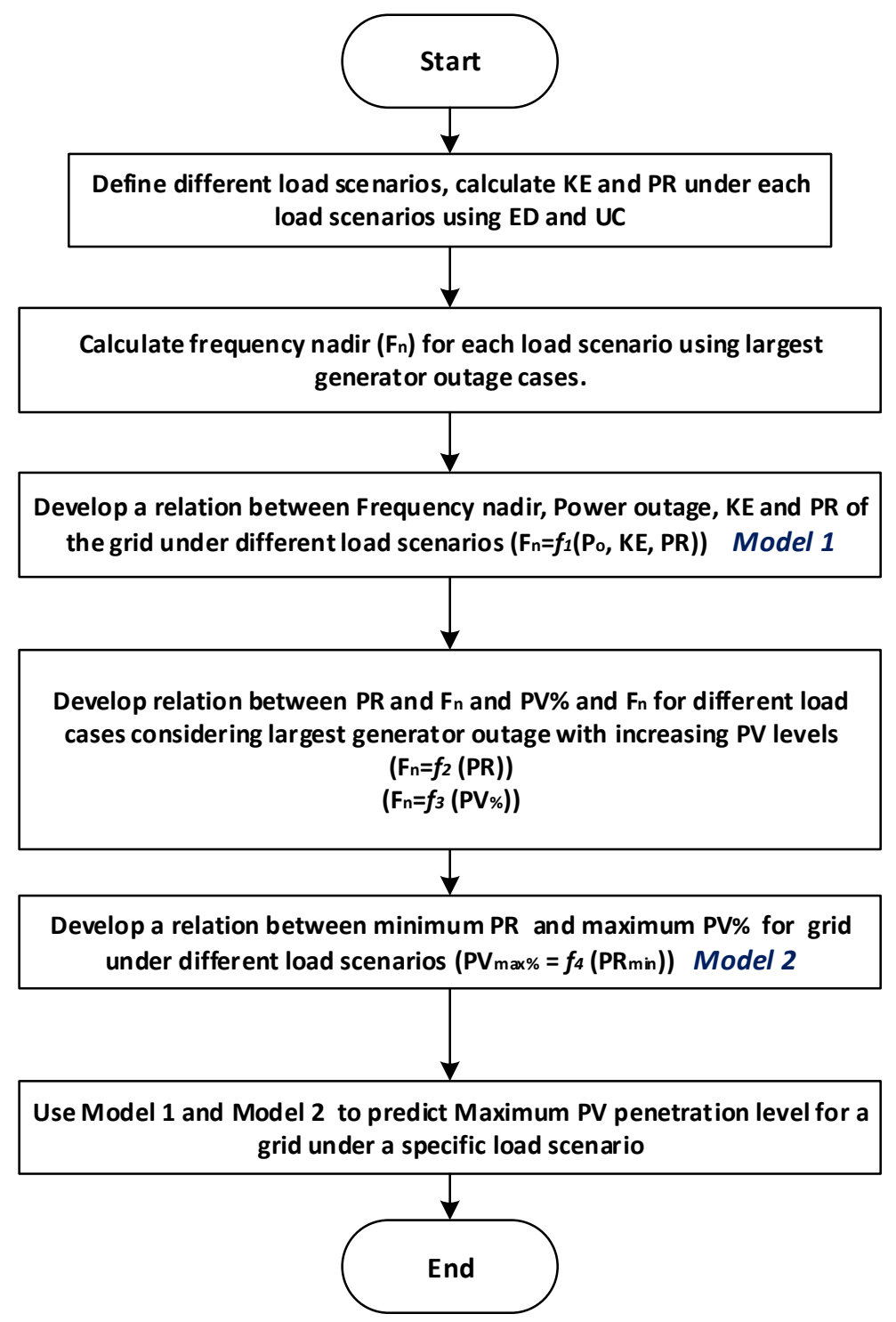

Figure 8. Flowchart for frequency nadir-based $\mathrm{PV}_{\max \%}$ estimation.

\subsection{Stage 2: Voltage Severity Index-Based $P V_{\text {max } \%}$ Estimation}

In the second stage of $P V_{m a x}$ estimation method, voltage severity index (VSI) defined in Section 3.2 is used as deterministic factor. The calculated values of VSI for over a number of load scenarios created by varying the generation mix in the system are used to derive a security boundary for the test system. The steps of assessment of the VSI based security boundary is as follows:

- $\quad$ Step 1: Create a number of operating scenarios by varying the generation mix in the test system. For obtaining various combinations, CPP is varied from $0-100 \%$. HVDC sources are considered in the test system with a variation of $0-30 \%$ with both import and export conditions. The solar PV additions were varied between $0-60 \%$. All the HVDC and PV penetration mix are calculated with respect to total system demand under respective load scenarios whereas CPP levels are calculated based on their total installed capacity.

- $\quad$ Step 2: The values of VSI are calculated using Equation (3) explained in Section 3.2. Various fault cases as listed in Table 1 were considered to calculate VSI values under all generation combinations with various operating conditions.

- Step 3: Using the calculated VSI values and generation mix of the system, a security boundary is derived for the studied test system. This boundary can be used to predict 
$\mathrm{PV}_{\max } \%$ which ensures voltage security of the test system corresponding to the chosen operating condition/load scanario.

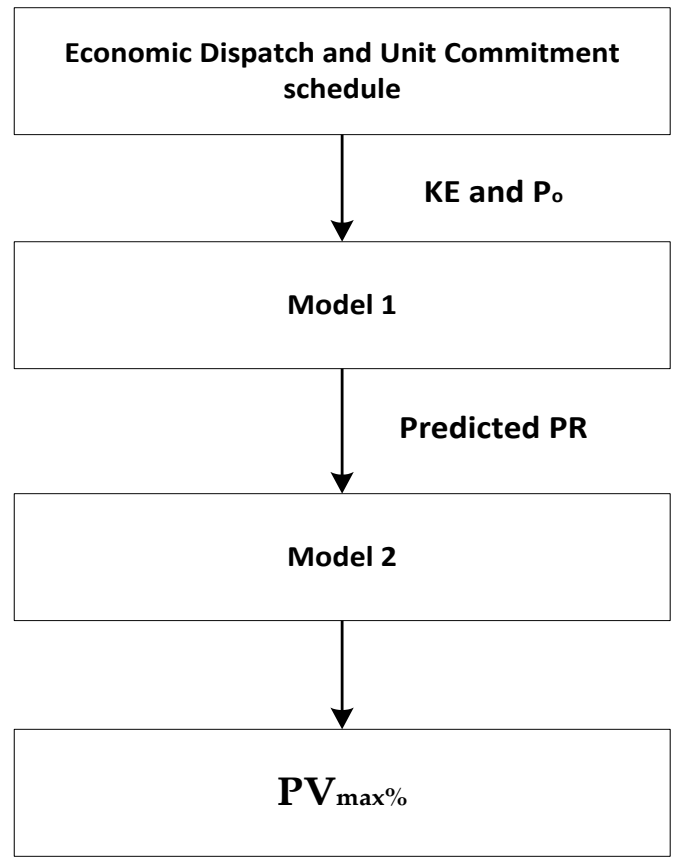

Figure 9. Combined approach of model 1 and model 2 to predict $P V_{\max } \%$.

\subsection{Combined Utilization of Stage 1 and Stage 2 for $P V_{\max } \%$ Estimation}

Stage 1 and stage 2 of the proposed $P V_{\max }$ estimation tool are decoupled since they both depend on two different deterministic parameters such as $F_{n}$ and VSI. Figure 10 represents the flowchart of the combined estimation process which uses both the strategies together to compute maximum PV penetration level in the power grid that ensures both frequency and voltage security of the system.

\section{Frequency based}

\section{Obtain Model 1 using frequency nadir, KE, Power outage and PR}

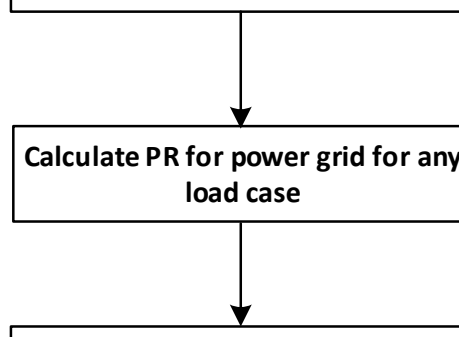

Calculate Maximum PV Level from PR using model 2 (PV $\max 1$ )
Voltage based

Calculation of generation mix (CPP, HVDC and PV)

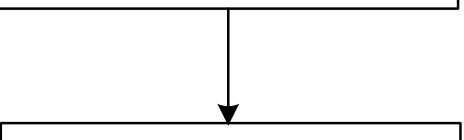

Calculate VSI for power grid and develop security boundary

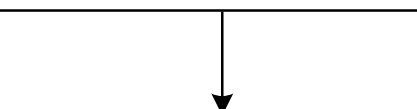

Calculate Maximum PV Level (PV max 2)

Figure 10. Flowchart for combined $P V_{\max }$ estimation. 
The transmission system operators are free to use either one of the stages to estimate $\mathrm{PV}_{\max \%}$ depending on their requirement of maintaining a frequency secure system or a voltage secure system or both by following respective methodology.

\section{Results and Discussion}

The proposed tool is applied to IEEE 39 bus test system constructed considering detailed dynamic models of all components in DIgSILENT PowerFactory simulation platform. Extensive number of dynamic simulations are performed under various case studies and python scripts are used to automate the simulation processes. The total installed capacity of the system is 14,535 MW and peak demand is $6097 \mathrm{MW}$ (IEEE TF, 2013). The loads are modeled as $100 \%$ constant power model for active power and $100 \%$ constant impedance model for reactive power for the stage 1 analysis of the proposed tool. Various load scenarios are created to obtain different values of KE and PR combinations by committing and dispatching the synchronous generators present in the test system. HVDC connections are also considered while creating various load scenarios, but their variations were not considered significant for stage 1 estimation since they do not participate in active power changes during frequency events whereas they were used as one of the important parameters for stage 2 of the proposed estimation approach. Moreover, it is important to note that the PV systems added to the test system for increasing the PV levels are not equipped with virtual inertia control or any other active power control capabilities unless mentioned otherwise.

\subsection{Stage 1: Frequency Nadir-Based $P V_{\text {max } \%}$ Estimation}

The simulation results for stage 1 of the $\mathrm{PV}_{\mathrm{max} \%}$ estimation framework is presented in this subsection. Eight different load scenarios are created for analysis purposes which varies from a minimum load of $4627 \mathrm{MW}$ to a maximum load of $6097 \mathrm{MW}$ with various HVDC imports and exports level. As a first step, frequency nadir $\left(F_{n}\right)$ values are calculated for each load case by considering largest generator outage in the system and the obtained results are tabulated as follows (Table 3):

From the values of Table 3, model 1, the mathematical relation between $F_{n}$ with respect to $\mathrm{P}_{0}, \mathrm{KE}$ and $\mathrm{PR}$ is obtained using multi-variable regression analysis with $95 \%$ confidence level and is expressed using Equation (11) as follows:

$$
\mathrm{F}_{\mathrm{n}}=-0.007\left(\mathrm{P}_{\mathrm{o}}\right)+0.00071(\mathrm{KE})+0.00082(\mathrm{PR})
$$

The adjusted R-square which is an indicator of goodness of fit was obtained as $93 \%$ for the obtained regression relation, hence the coefficients obtained from the multi-variable regression analysis is acceptable and Equation (11) can be used for further analysis of stage 1 of the proposed estimation tool.

Table 3. Summary of $P_{0}, K E, P R$ and $F_{n}$ values for various load scenarios.

\begin{tabular}{ccccc}
\hline Load Scenarios & $\begin{array}{c}\mathbf{P}_{\mathbf{0}} \\
(\mathbf{M W})\end{array}$ & $\begin{array}{c}\text { KE } \\
\mathbf{( M W s )}\end{array}$ & $\begin{array}{c}\text { PR } \\
\mathbf{( M W )}\end{array}$ & $\begin{array}{c}\mathbf{F}_{\mathbf{n}} \\
\mathbf{( H z )}\end{array}$ \\
\hline Load Case 1 & 1000 & $78,269.5$ & 894.2 & 46.602 \\
Load Case 2 & 660 & $75,669.7$ & 1143.6 & 48.788 \\
Load Case 3 & 630 & $74,819.5$ & 991.4 & 49.14 \\
Load Case 4 & 800 & $74,789.5$ & 1490.4 & 48.56 \\
Load Case 5 & 900 & $75,839.8$ & 807.9 & 47.046 \\
Load Case 6 & 550 & $78,260.5$ & 1302.8 & 49.362 \\
Load Case 7 & 650 & $75,629.8$ & 1136.4 & 49.134 \\
Load Case 8 & 508 & $74,689.5$ & 287.3 & 48.804 \\
\hline
\end{tabular}

As the next step, the solar PV penetration level is increased in steps for each load case and the penetration levels are calculated using Equation (7) as explained in Section 4.1. In every step, CoI frequency nadir values are measured by applying largest generator outage cases in order to 
obtain a relation between PV penetration level and frequency nadir as well as PR and frequency nadir for individual load cases. The lower limit of allowable frequency nadir is kept as 49.2 $\mathrm{Hz}$, based on similar practices for small-scale power systems. It is important to note that the generator G 01 in test system which indicate the rest of the interconnected system in the USA and Canada do not provide any governor action for frequency support to the system. Now, setting the value of $F_{n}=49.2 \mathrm{~Hz}$, using Equation (8)-(9), the mathematical formula is derived for each load case to calculate $\mathrm{PR}_{\min }$ and $\mathrm{PV}_{\max \%}$. The results are summarized in Tables 4 and 5.

Table 4. Summary of calculated $\mathrm{PR}_{\mathrm{min}}$ values for various load scenarios.

\begin{tabular}{ccc}
\hline Load Scenarios & $\begin{array}{c}\text { Mathematical Relation } \\
\text { between } \mathbf{F}_{\mathbf{n}} \text { and PR }\end{array}$ & $\begin{array}{c}\mathbf{P R}_{\mathbf{m i n}} \\
\mathbf{( M W )}\end{array}$ \\
\hline Load Case 1 & $\mathrm{F}_{\mathrm{n}}=-0.000102(\mathrm{PR})+49.32$ & 1176.4 \\
Load Case 2 & $\mathrm{F}_{\mathrm{n}}=-0.000181(\mathrm{PR})+49.42$ & 1222.22 \\
Load Case 3 & $\mathrm{F}_{\mathrm{n}}=-0.000074(\mathrm{PR})+49.31$ & 1486.48 \\
Load Case 4 & $\mathrm{F}_{\mathrm{n}}=-0.000044(\mathrm{PR})+49.29$ & 2045.45 \\
Load Case 5 & $\mathrm{F}_{\mathrm{n}}=-0.000091(\mathrm{PR})+49.28$ & 879.12 \\
Load Case 6 & $\mathrm{F}_{\mathrm{n}}=-0.000058(\mathrm{PR})+49.35$ & 2586.2 \\
Load Case 7 & $\mathrm{F}_{\mathrm{n}}=-0.000057(\mathrm{PR})+49.3$ & 1818.18 \\
Load Case 8 & $\mathrm{F}_{\mathrm{n}}=0.000067(\mathrm{PR})+49.19$ & 597.01 \\
\hline
\end{tabular}

Table 5. Summary of calculated $P V_{\max \%}$ values for various load scenarios.

\begin{tabular}{ccc}
\hline Load Scenarios & $\begin{array}{c}\text { Mathematical Relation } \\
\text { between } \mathbf{F}_{\mathbf{n}} \text { and } \mathbf{P V}_{\%}\end{array}$ & $\begin{array}{c}\mathbf{P V}_{\text {max\% }} \\
\mathbf{( \% )}\end{array}$ \\
\hline Load Case 1 & $\mathrm{F}_{\mathrm{n}}=-0.0608\left(\mathrm{PV}_{\%}\right)+48.73$ & 12 \\
Load Case 2 & $\mathrm{F}_{\mathrm{n}}=-0.0701\left(\mathrm{PV}_{\%}\right)+49.16$ & 14.74 \\
Load Case 3 & $\mathrm{F}_{\mathrm{n}}=-0.0340\left(\mathrm{PV}_{\%}\right)+49.37$ & 22.37 \\
Load Case 4 & $\mathrm{~F}_{\mathrm{n}}=-0.0171\left(\mathrm{PV}_{\%}\right)+48.95$ & 40.61 \\
Load Case 5 & $\mathrm{F}_{\mathrm{n}}=-0.0615\left(\mathrm{PV}_{\%}\right)+48.64$ & 10.4 \\
Load Case 6 & $\mathrm{F}_{\mathrm{n}}=-0.0203\left(\mathrm{PV}_{\%}\right)+49.23$ & 42.85 \\
Load Case 7 & $\mathrm{F}_{\mathrm{n}}=-0.0314\left(\mathrm{PV}_{\%}\right)+49.49$ & 33.82 \\
Load Case 8 & $\mathrm{F}_{\mathrm{n}}=-0.1632\left(\mathrm{PV}_{\%}\right)+49.42$ & 8.7 \\
\hline
\end{tabular}

In order to obtain the mathematical relation between $\mathrm{PR}_{\min }$ and $\mathrm{PV}_{\mathrm{max}}$, a linear regression model is developed using the values from Tables 4 and 5. The relation obtained is given in Equation (12) as follows:

$$
\mathrm{PV}_{\max \%}=0.02071\left(\mathrm{PR}_{\min }\right)-7.391
$$

The regression model gave a fit of $92.8 \%$, hence proving that minimum PR and maximum PV penetration level in a system are highly correlated with each other. Figure 11 depicts a plot between $\mathrm{PR}_{\min }$ and $P V_{\max } \%$ showing the dependency of both parameters with each other. 


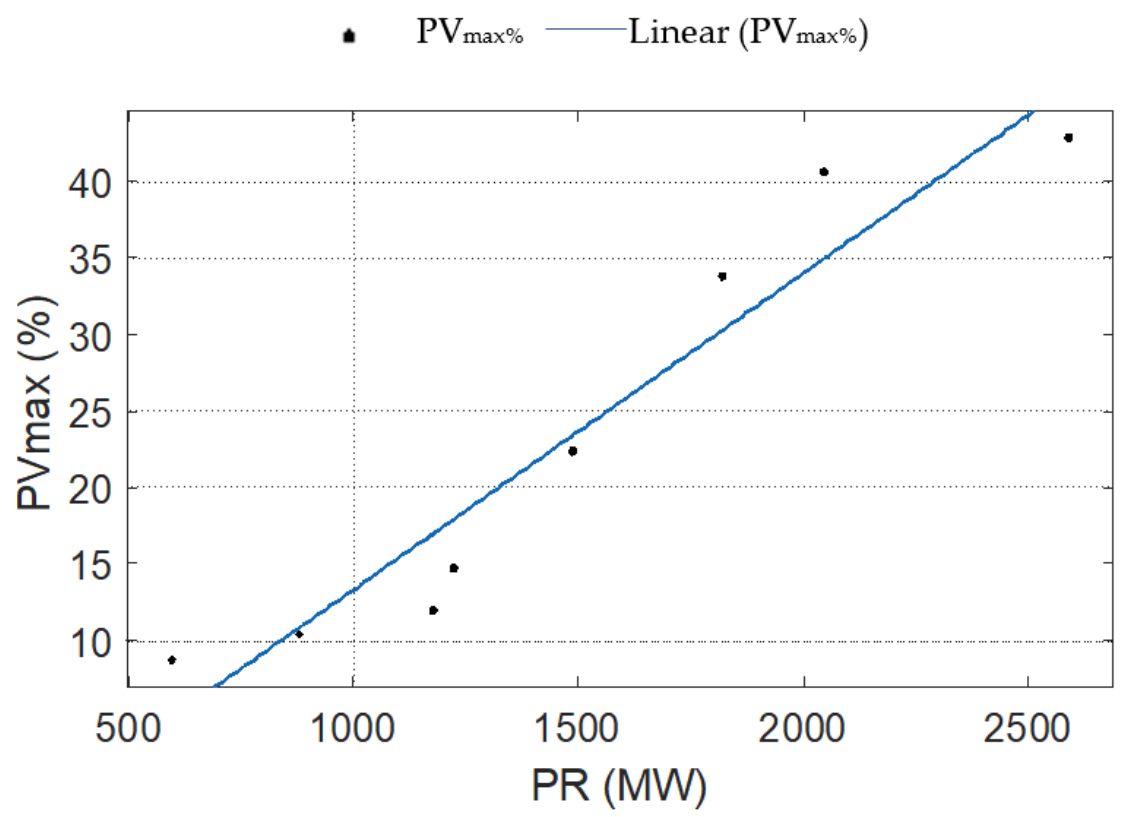

Figure 11. Maximum PV penetration level vs. power reserve of the system.

\subsection{Stage 2: VSI-Based $P V_{\max \%}$ Estimation}

This case study mainly aimed at providing a deep insight of how to assess the least possible presence of conventional power plants under high penetration of solar PV energy. The test system is further modified by introducing cross-border power exchange through HVDC links in order to provide various combinations of generation mix. As mentioned in Section 2, the phasing out of CPPs are done by adding PV into the system where the PV penetration level goes up to $60 \%$ (calculated with respect to the total system demand) above which the system becomes highly unstable due to the significant reduction of primary ancillary services from CPPs such as reactive power reserve, active power reserve, etc. Moreover, the power exchange through HVDC interconnections is quantified in terms of total system load and both the import and export scenarios are considered for the studies.

A vast range of operating conditions involving a generation mix of CPP, PV and HVDC and various fault cases as listed in Table 1 were considered to predict the security margin of the test system. The dynamic voltage security criterion explained in Section 3.2 is used to obtain the security boundary shown in Figure 12 which illustrates the influence of CPPs on voltage security of the system for various fault conditions by dividing the entire operating conditions in upper zone of insecure cases and lower secure zone. In the figure, the $\mathrm{x}$ and $\mathrm{y}$ axes represent the power share from PV and HVDC calculated with respect to the total system demand, respectively, whereas the $\mathrm{z}$ axis represents the power generation share from CPP in MW with respect to the total installed capacity of all CPPs present in the system. As expected, the test system is secure with more CPPs at lower PV share characterized by higher security margin.

The impact of HVDC power exchange on dynamic voltage security is another observation that can be made from Figure 12. In the case of HVDC import (shown as negative in Figure 12), since there is more power generation available, the power share from CPPs can be less compared to the export case. Additionally, reactive power consumption is higher due to higher reactive power losses in transmission system during fault in case of import thereby affecting the voltage security of the system. Hence, security level is relatively less in case of HVDC import in comparison with the export case and is clearly seen in Figure 12. 


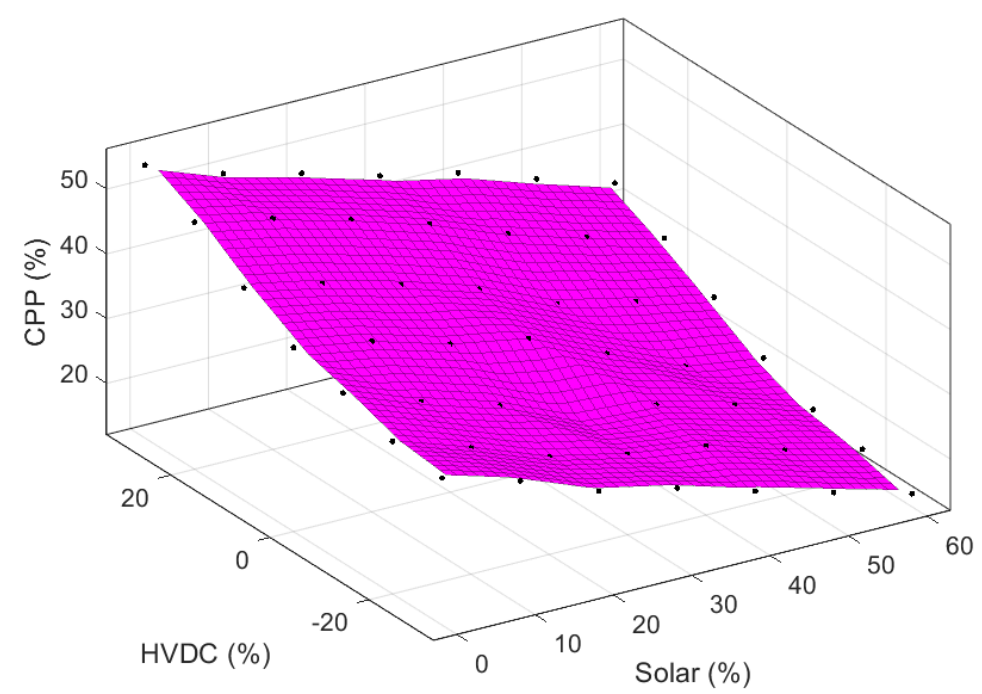

Figure 12. Voltage security boundary.

\subsection{Validation of Proposed $P V_{\max \%}$ Estimation Tool}

To validate the proposed estimation tool, a number of sample load scenarios are considered for two different power systems: IEEE 39 bus system and Gujarat state power grid of India. Gujarat, with a total installed capacity of $34 \mathrm{GW}$, is one of the RE rich states in India with $29 \%$ of total installed capacity derived from renewables. As of now, Gujarat grid has 7\% solar PV penetration and the system was modified to accommodate higher PV penetration levels to indicate future scenarios for simulation purposes. In the first step of validation, model 1 and model 2 are determined for both the test systems and $\mathrm{PV}_{\max \%}$ is obtained using the estimation approach as explained in Section 4 . In the second step of the validation, dynamic time-domain simulations are carried out by creating same contingencies under same load scenarios as used for first step, and evaluated the maximum possible PV penetration level that the systems can handle without disturbing its frequency/voltage stability. As the final step, the difference between output using proposed tool and dynamic simulation is calculated with the help of the following Equation (13):

$$
\text { Deviation } \%_{\%}=\frac{P V_{\max \%, \text { tool }}-\mathrm{PV}_{\max \%, \operatorname{sim}}}{P V_{\max \%, \operatorname{sim}}} \times 100 \%
$$

where $P V_{\text {max } \% \text {,tool }}$ and $P V_{\max \% \text { sim }}$ represents the maximum PV penetration level obtained from the proposed tool as explained in Section 4 and time-domain simulation, respectively. Table 6 shows a comparison between the obtained results. From the results, it is observed that the deviations between $\mathrm{PV}_{\max }$ obtained using the tool and the dynamic simulation are less than $5 \%$ for all evaluated load scenarios of both test systems. Thus it can be inferred that the proposed tool can successfully predict maximum instantaneous PV penetration level that a system can securly handle for any operating conditions.

Table 6. Validation results for studied power systems.

\begin{tabular}{cccc}
\hline Load Case & $\begin{array}{c}\mathbf{P V}_{\text {max }} \\
\text { (Using Tool) }\end{array}$ & $\begin{array}{c}\mathbf{P V}_{\text {max }} \\
\text { (Using Simulation) }\end{array}$ & $\begin{array}{c}\text { Deviation } \\
\mathbf{( \% )}\end{array}$ \\
\hline Load Case 1 & \multicolumn{2}{c}{ IEEE 39 bus system } & \\
Load Case 2 & 41.5 & 43 & 3.4 \\
Load Case 3 & 14.42 & 15 & 3.86 \\
& 26.7 & 28 & 4.6 \\
Load Case 1 & \multicolumn{2}{c}{ Gujarat State Grid } \\
Load Case 2 & 45.1 & 47 & 4.31 \\
Load Case 3 & 28.9 & 30 & 3.66 \\
\hline
\end{tabular}




\subsection{Validation of Proposed $P V_{\max } \%$ Estimation Approach in Presence of Emulated PV Inertia}

In this section, the validation results are presented for the proposed tool applied to IEEE 39 bus system considering emulated inertial suupport from PV power plants. For inertia emulation, $20 \%$ of PV curtailment is considered and the available amount of PV power for frequency support is added to the total PR of the system during the calculation procedure of $\mathrm{PV}_{\max }$. Model 1 and model 2 are obtained using the method explained in Section 4.1 and $\mathrm{PV}_{\max } \%$ is estimated considering only frequency-based approach (stage 1). The obtained $P V_{\max }$ values for two diffrenet load cases are compared with the respective time-domain simulation-based results and the difference in output is calculated. The comparison is given in Table 7 below.

Table 7. Validation results for test system with emulated PV inertia.

\begin{tabular}{cccc}
\hline Load Case & $\begin{array}{c}\mathbf{P V}_{\text {max }} \\
\text { (Using Tool) }\end{array}$ & $\begin{array}{c}\mathbf{P V}_{\text {max }} \\
\text { (Using Simulation) }\end{array}$ & $\begin{array}{c}\text { Deviation } \\
\text { (\%) }\end{array}$ \\
\hline Load Case 1 & \multicolumn{2}{c}{ IEEE 39 bus system } \\
Load Case 2 & 33.1 & 35 & 5.4 \\
\hline
\end{tabular}

\section{Conclusions}

The research work presented in this paper proposes a new tool to estimate maximum permissible solar PV penetration level that can be integrated to a given power system. In this study, the impact of increased penetration of solar PV on transient stability, dynamic voltage stability/security and frequency stability of a power system are studied by considering a vast number of various fault conditions. From the results, the transient stability of the test system is found to be highly dependent on the fault proximity and fault duration and has both adverse and beneficial effects with higher PV levels. From dynamic voltage security analysis and frequency stability analysis, it is observed that the system security was severely affected by the PV-driven displacement of CPP at higher PV penetration levels. Thus, the developed $\mathrm{PV}_{\max \%}$ estimation tool can use both voltage and frequency behavior of the system individually or together depending on the requirement as mandated by the system operators.

In the first stage of the proposed tool, frequency nadir characteristics of the power system along with power reserve (PR) and kinetic energy (KE) are used to assess secure $\mathrm{PV}$ penetration threshold, provided the generation profile of the system is available from economic dispatch/unit commitment. Regression models are developed relating KE, PR, $\mathrm{F}_{\mathrm{n}}$ and $\mathrm{PV}_{\%}$ which can be used to evaluate $\mathrm{PV}_{\max }$ for any load scenarios without performing complete dynamic simulations of the system. Similarly, in the voltage-based $\mathrm{PV}_{\max } \%$ estimation stage, the results of the voltage security assessment of the power system are used to draw a voltage security boundary in terms of the generation mix which then can be used to find out secure and insecure operating conditions of the grid under various contingencies. The decoupled nature of the proposed tool makes it more flexible towards its applications in a system operator's point of view. The proposed tool is successfully validated using a number of operating load scenarios considered in two different power system models: IEEE 39 bus system and Gujarat state power grid in India. Additionally, the tool is validated considering virtual inertial support and governor-like response from integrated solar PV plants in the power system. The validation results demonstrate that the proposed $\mathrm{PV}_{\mathrm{max}}$ estimation tool can be implemented in any power grid. A transmission system operator may use these predicted $\mathrm{PV}_{\max } \%$ values to correct unit commitment and economic dispatch schedule if there is a possible risk in either frequency response/voltage security or both.

Author Contributions: The project conceptualization, methodology and investigation were done by D.L.J. under the supervision of Z.H.R. and guidance from B.C.P. Writing — original draft preparation 
by D.L.J. Writing - review and editing by Z.H.R. and B.C.P. Funding acquisition by Z.H.R. and B.C.P. All authors have read and agreed to the published version of the manuscript.

Funding: This work was funded in part by INDIA-UK Centre for Education and Research in Clean Energy (IUCERCE) and in part by "Joint UK-India Clean Energy Centre (JUICE)" which is funded by the RCUK's Energy Programme under Grant EP/P003605/1.

Institutional Review Board Statement: Not applicable.

Informed Consent Statement: Not applicable.

Acknowledgments: This work was supported in part by INDIA-UK Centre for Education and Research in Clean Energy (IUCERCE) and in part by "Joint UK-India Clean Energy Centre (JUICE)" which is funded by the RCUK's Energy Programme under Grant EP/P003605/1.

Conflicts of Interest: The authors declare no conflict of interest.

\section{Nomenclature}

The following abbreviations and nomenclatures are used in this manuscript:

$\mathrm{F}_{\mathrm{n}} \quad$ frequency nadir

$\mathrm{H}_{\mathrm{i}} \quad$ inertia constant

$\mathrm{PR}_{\min } \quad$ minimum power reserve

$\mathrm{PV}_{\%} \quad$ PV penetration level

$\mathrm{PV}_{\max } \%$ maximum PV penetration level

$P_{\text {gen,i }} \quad$ generator actual power output

$P_{\text {rated,i }}$ generator rated power output

$\mathrm{S}_{\mathrm{i}} \quad$ generator MVA rating

$n \quad$ number of online generators

$n_{g} \quad$ number of generators with governors

$\Delta \delta_{\max } \quad$ maximum rotor angle deviation

$\mathrm{CPP} \quad$ conventional power plant

KE kinetic energy

PFR primary frequency reserves

$P_{\mathrm{O}} \quad$ power outage

PR power reserve

PV photovoltaic

REEC_B renewable energy electrical control module

REGC_A renewable energy generator/converter module

REMTF renewable energy modeling task force

REPC_A renewable energy plant control module

RES renewable energy sources

RoCoF rate of change of frequency

TSI transient stability index

TSO transmission system operator

UFLS under frequency load shedding

VSI voltage severity index

WECC Western Electricity Coordinating Council

\section{References}

1. Whiteman, A.; Akande, D.; Elhassan, N.; Escamilla, G.; Lebedys, A.; Arkhipova, I. Renewable Capacity Statistics 2021; International Renewable Energy Agency (IRENA): Abu Dhabi, United Arab Emirates, 2021; Available online: https://www.irena.org/ publications/2021/March/Renewable-Capacity-Statistics-2021 (accessed on 30 April 2021).

2. REN21.2020. Renewables 2020 Global Status Report; REN21 Secratariet: Paris, France. Available online: https://www.ren21.net/ wp-content/uploads/2019/05/gsr_2020_full_report_en.pdf (accessed on 30 April 2021).

3. Kabir, E.; Kumar, P.; Kumar, S.; Adelodun, A.A.; Kim, K.-H. Solar Energy: Potential and Future Prospects. Renew. Sustain. Energy Rev. 2018, 82, 894-900. [CrossRef]

4. Aleem, S.A.; Hussain, S.M.S.; Ustun, T.S. A Review of Strategies to Increase PV Penetration Level in Smart Grids. Energies 2020, 13, 636. [CrossRef]

5. Shah, R.; Mithulananthan, N.; Bansal, R.; Ramachandaramurthy, V. A Review of Key Power System Stability Challenges for Large-Scale PV Integration. Renew. Sustain. Energy Rev. 2015, 41, 1423-1436. [CrossRef] 
6. Achilles, S.; Schramm, S.; Bebic, J. Transmission System Performance Analysis for High-Penetration Photovoltaics; GE Global Research and NREL, US Department of Energy: Golden, CO, USA, 2008. [CrossRef]

7. Eftekharnejad, S.; Vittal, V.; Heydt, G.T.; Keel, B.; Loehr, J. Impact of Increased Penetration of Photovoltaic Generation on Power Systems. IEEE Trans. Power Syst. 2013, 28, 893-901. [CrossRef]

8. Mansouri, N.; Lashab, A.; Sera, D.; Guerrero, J.M.; Cherif, A. Large Photovoltaic Power Plants Integration: A Review of Challenges and Solutions. Energies 2019, 12, 3798. [CrossRef]

9. Eltawil, M.A.; Zhao, Z. Grid-Connected Photovoltaic Power Systems: Technical and Potential Problems-A Review. Renew. Sustain. Energy Rev. 2010, 14, 112-129. [CrossRef]

10. Australian Energy Market Operator. Black System South Australia 28 September 2016: Final Report. 2017. Available online: https: / / apo.org.au/node/74886 (accessed on 10 May 2021).

11. Mohseni, M.; Islam, S.M. Review of International Grid Codes for Wind Power Integration: Diversity, Technology and a Case for Global Standard. Renew. Sustain. Energy Rev. 2012, 16, 3876-3890. [CrossRef]

12. Arulkumar, K.; Palanisamy, K.; Vijayakumar, D. Recent Advances and Control Techniques in Grid Connected PV System-A Review. Int. J. Renew. Energy Res. 2016, 6, 1037-1049.

13. Rather, Z.H.; Chen, Z.; Thogersen, P. Challenge of Primary Voltage Control in Large Scale Wind Integrated Power System: A Danish Power System Case Study. In Proceedings of the IEEE PES ISGT Europe 2013, Lyngby, Denmark, 6-9 October 2013; pp. 1-5. [CrossRef]

14. Oprea, S.-V.; Bâra, A. Analyses of Wind and Photovoltaic Energy Integration from the Promoting Scheme Point of View: Study Case of Romania. Energies 2017, 10, 2101. [CrossRef]

15. Ahmadi, H.; Ghasemi, H. Maximum Penetration Level of Wind Generation Considering Power System Security Limits. IET Gener. Transm. Distrib. 2012, 6, 1164-1170. [CrossRef]

16. Tamimi, A.A.; Pahwa, A.; Starrett, S.; Williams, N. Maximizing Wind Penetration Using Voltage Stability Based Methods for Sizing and Locating New Wind Farms in Power System. In Proceedings of the IEEE PES General Meeting, Minneapolis, MN, USA, 25-29 July 2010; pp. 1-7. [CrossRef]

17. Coath, G.; Dabbagh, M. Effect of Steady State Wind Turbine Generator Models on Power Flow Convergence and Voltage Stability Limit. Australasian Universities Power Engineering Conference, Tasmania, Australia, 25-28 September 2005.

18. Sreedharan, S.; Ongsakul, W.; Singh, J.G.; Wartana, I.M.; Buayai, K. Development of PSO Based Control Algorithms for Maximizing Wind Energy Penetration. In Proceedings of the 2011 IEEE Power and Energy Society General Meeting, San Diego, CA, USA, 24-28 July 2011; pp. 1-6. [CrossRef]

19. Tamimi, A.A.; Pahwa, A.; Starrett, S. Effective Wind Farm Sizing Method for Weak Power Systems Using Critical Modes of Voltage Instability. IEEE Trans. Power Syst. 2012, 27, 1610-1617. [CrossRef]

20. Kaldellis, J.K.; Kavadias, K.A.; Filios, A.E. A New Computational Algorithm for the Calculation of Maximum Wind Energy Penetration in Autonomous Electrical Generation Systems. Appl. Energy 2009, 86, 1011-1023. [CrossRef]

21. Yu, H.Y.; Bansal, R.C.; Dong, Z.Y. Fast Computation of the Maximum Wind Penetration Based on Frequency Response in Small Isolated Power Systems. Appl. Energy 2014, 113, 648-659. [CrossRef]

22. Masood, N.A.; Yan, R.; Saha, T. A New Tool to Estimate Maximum Wind Power Penetration Level: In Perspective of Frequency Response Adequacy. Appl. Energy 2015, 154, 209-220. [CrossRef]

23. Western Electricity Coordinating Council (WECC) Renewable Energy Modeling Task Force. (2010, August) WECC PV plant power flow modeling guidelines. Available online: https:/ / www.wecc.biz/Reliability/WECCPVPlantPowerFlowModelingGuide.pdf (accessed on 1 November 2021).

24. Western Electricity Coordinating Council (WECC) Renewable Energy Modeling Task Force. (2014, January) WECC second generation wind turbine models. Available online: https:/ / www.wecc.biz/Reliability/WECCSecondGenerationWindTurbineModels0 12314.pdf (accessed on 1 November 2021).

25. Munkhchuluun, E.; Meegahapola, L.; Vahidnia, A. Impact on Rotor Angle Stability with High Solar-PV Generation in Power Networks. In Proceedings of the 2017 IEEE PES Innovative Smart Grid Technologies Conference Europe (ISGT-Europe), Turin, Italy, 26-29 September 2017; pp. 1-6. [CrossRef]

26. Vittal, E.; O'Malley, M.; Keane, A. Rotor Angle Stability with High Penetrations of Wind Generation. IEEE Trans. Power Syst. 2012, 27, 353-362. [CrossRef]

27. Meegahapola, L.; Littler, T. Characterisation of Large Disturbance Rotor Angle and Voltage Stability in Interconnected Power Networks with Distributed Wind Generation. IET Renew. Power Gener. 2015, 9, 272-283. [CrossRef]

28. Powertech Labs. DSATools: Dynamic Security Assessment Software. Available online: https://www.dsatools.com (accessed on 10 May 2021).

29. Zhang, Y.; Zhu, S.; Sparks, R.; Green, I. Impacts of Solar PV Generators on Power System Stability and Voltage Performance. In Proceedings of the 2012 IEEE Power and Energy Society General Meeting, San Diego, CA, USA, 22-26 July 2012; pp. 1-7. [CrossRef]

30. Zhang, Y.; Mensah-Bonsu, C.; Walke, P.; Arora, S.; Pierce, J. Transient Over-Voltages in High Voltage Grid-Connected PV Solar Interconnection. In Proceedings of the IEEE PES General Meeting, Minneapolis, MN, USA, 25-29 July 2010; pp. 1-6. [CrossRef] 
31. Xue, Y.; Manjrekar, M.; Lin, C.; Tamayo, M.; Jiang, J.N. Voltage Stability and Sensitivity Analysis of Grid-Connected Photovoltaic Systems. In Proceedings of the 2011 IEEE Power and Energy Society General Meeting, Detroit, MI, USA, 24-28 July 2011 ; pp. 1-7. [CrossRef]

32. Eber, E.; Corbus, D. Hawaii Solar Integration Study: Executive Summary; National Renewable Energy Laboratory, US Department of Energy: Golden, CO, USA, 2013.

33. Gevorgian, V.; Booth, S. Review of PREPA Technical Requirements for Interconnecting Wind and Solar Generation; National Renewable Energy Laboratory, US Department of Energy: Golden, CO, USA, 2013. [CrossRef]

34. Lacommare, K.S.H. Review of the Recent Frequency Performance of the Eastern, Western and ERCOT Interconnections; Lawrence Berkeley National Laboratory: Berkeley, CA, USA, 2010. [CrossRef]

35. Kundur, P. Power System Stability and Control; McGraw Hill: New York, NY, USA, 1994; pp. 271-314, 959-1024. 